\title{
FLORA LIQUÉNICA DE LOS SABINARES ESPAÑOLES
}

\author{
Mª Andrea MONSÓ SENABRE
}

\begin{abstract}
RESUMEN: Se aporta una primera nota de 14 líquenes epífitos que se desarrollan sobre corteza de sabinares albares de Juniperus hemisphaerica-thuriferae Rivas-Martínez (1969), del páramo calizo de Prádena (Segovia, España).

Palabras clave: líquenes epífitos, sabinares albares, Prádena, España.
\end{abstract}

SUMMARY: Lichens of Juniperus thurifera-forest from Spain. A first study of 14 epiphytic lichens from Prádena is stated, growing on Juniperus thurifera L. bark of the association Juniperetum hemisphaerico-thuriferae Rivas-Martínez, (1969) of calcareous moorland Prádena (Segovia, Spain).

Key word: epiphytic lichens, Juniperus sabina-forest, Prádena, Spain.

\section{INTRODUCCIÓN}

Este trabajo es una aportación acerca del contenido florístico liquénico epífito que se desarrolla en las parameras ibéricas donde habitan sabinares albares correspondientes a la serie supramediterránea de la sabina albar Juniperus thurifera L.: Iuniperetum hemisphaerica-thuriferae Rivas-Martínez (1969). Se trata ecosistemas antiguos, relictos y resistentes en localidades siempre continentales de la Península Ibérica, que cuando se degradan dejan paso a pastizales y tomillares dispersos de posible aprovechamiento ganadero.

El área de estudio se encuentra incluída en la provincia corológica CastellanoMaestrazgo-Manchega, Sector Celtibérico-Alcarreño. Pertenece a la provincia de Segovia y está situada a unos $1200 \mathrm{~m}$. de altitud, en los páramos de Prádena, en el Sistema Central, siendo sus coordenadas UTM 30TVL4253.

El sustrato geológico está datado como perteneciente al Cretácico superior de facies continental y constituído por rocas metamórficas. Domina la terra fusca, pobre en humus en suelo tipo cambisol cálcico.

La corteza de Juniperus thurifera L., se caracteriza por ser una corteza de poco grosor que se desprende en tiras y por ser rugosa permite el asentamiento de diversas especies de líquenes. 


\section{CATÁl OGO FLORÍSTICO}

El catálogo florístico consta de especies epífitas en su mayoría. Para la determinación de los distintos táxones se han utilizado las obras de Hawsworth, James \& Coppins (1980), Poelt (1969), Poelt \& Vezda (1977), Poelt \& Vezda (1981) y Wirth (1980).

Anaptychia ciliaris (L.) Koerb.

SEGOVIA: Prádena. 29-VI-89. Corticícola. Sobre Juniperus thurifera aislado.

Cetraria juniperina (L.) Ach.

SEGOVIA: Prádena. 4-XI-88. Frecuente en zonas más húmedas del sabinar, creciendo entre la hierba y sobre el tronco caído de Juniperus thurifera.

Fulgensia fulgens (Sw.) Elenk.

SEGOVIA: Prádena. 13-I-89. Especie muy escasa recolectada en las zonas de mayor humedad, al pié de tronco de Juniperus thurifera, sobre estrato muscinal.

Parmelia scortea Ach.

SEGOVIA: Prádena. 29-VI-89. Corticícola y saxícola con distribución cosmopolita sobre Juniperus thurifera.

Parmelia subaurífera Nyl.

SEGOVIA: Prádena. 13-I-89. Estrechamente adherido a la corteza de las ramas más pequeñas de Juniperus thurifera.

Pertusaria paramerae Crespo \& Vezda

SEGOVIA: Prádena. 29-VI-89. Sobre corteza de Juniperus thurifera.

Physcia adscendens (Fr.) H. Olivier

SEGOVIA: Prádena. 4-XI-88. Sobre corteza semidesprendida de Juniperus thurifera.

Physcia aipolia (Ehrh.) Hampe

SEGOVIA: Prádena. 13-I-89. Sobre tronco y ramas gruesas de Juniperus thurifera. Elemento de amplia distribución.

Physcia leptalea (Ach.) DC.

SEGOVIA: Prádena. 4-XI-88. En oquedades de tronco de Juniperus thurifera.

Physconia grisea (Lamb.) Poelt.

SEGOVIA: Prádena. 29-VI-89. Aparece frecuente y abundante sobre roca caliza, también sobre corteza de Juniperus thurifera.

Physconia pulverulenta (Schreb.) Poelt.

SEGOVIA: Prádena. 29-VI-89. Sobre corteza de Juniperus thurifera. 
Psora scalaris Ach.

SEGOVIA: Prádena. 29-VI-89. Sobre la corteza, en la base de Juniperus thurifera

Solorina saccata (L.) Ach.

SEGOVIA: Prádena. 29-VI-89. Sobre la base musgosa de Juniperus thurifera.

Xanthoria parietina (L.) Beltr.

SEGOVIA: Prádena. 29-VI-89. Se desarrolla en las zonas más secas, apareciendo bien representada sobre ramas y tronco de Juniperus thurifera.

\section{BIBLIOGRAFÍA}

HAWSWORTH, D.L., P.W. JAMES \& B.J. COPPINS -1980- Checklist of Britisch LichenForming. Liquenicolous and allied fungi. Liquenologist, 12 (1): 1-115.

POELT, J. -1969-Bestimmungschlüssel europaischer Flechten. Ed. J. Cramer. Vaduz.

POELT, J. \& A. VEZDA -1977-Bestimmungschlüssel europaischer Flechten.Ergänzungsheft.

I. Ed. J. Cramer. Vaduz.

POELT, J. \& A. VEZDA-1981-Bestimmungschlüssel europaischer Flechten.Ergänzungsheft. II. Ed. J. Cramer. Vaduz.

RIVAS-MARTINEZ, S. -1969- Vegetatio hispanie. Notula I: El piso de vegetación de los bosques sabineros de los páramos. Juniperetum hemisphaerico thuriferae Rivas Martínez, As. nova. P. Inst. Biol. Apl., 46:5-34.

WIRTH, V. -1980- Flechtenflora. Stuttgart. Ulmer.

(Aceptado para su publicación en Junio de 1.990)

Dirección de la autora: Departamento de Producción Vegetal: Botánica y Protección Vegetal. E.U.I.T. Forestal. Universidad Politécnica de Madrid. 28040 - Madrid. 